\title{
Thermoxidative stabilization of poly(ethylene terephthalate) and alkyd Using dibutyltin diethanoate
}

\author{
Turoti Muyiwa $^{1}$, Gimba E Casmir ${ }^{2}$, Ocholi Odike ${ }^{2}$, Oti Chinedu ${ }^{1}$ \\ ${ }^{I}$ Department of Chemistry, Obafemi Awolowo University, Ile-Ife, Nigeria. \\ ${ }^{2}$ Department of Chemistry, Ahmadu Bello University, Zaria, Nigeria.
}

\begin{abstract}
The thermo-oxidative degradation of unstabilized and stabilized coatings of each of a saturated polyester and a poly (pentaerythritol-phthalate)based alkyd coatings separately pigmented with syncomine yellow 1630 have been studied. The test stabilizer was dibutyltin diethanoate employed at varying concentrations. The degradation of the coatings was monitored using color development, determination of gel content, stress-strain relationships, gloss retention and optical microscopy. The results showed that incorporating a concentration of 5 or $10 \times 10^{-4}$ mole \% of the tin ester can effectively stabilize both the polyester and alkyd coatings against thermo oxidative degradation.
\end{abstract}

Keywords: Polyester, alkyd, dibutyltindiethanoate, degradation, stabilizer,coating.

\section{Introduction}

Many properties of uncoated articles generally deteriorate faster under thermal exposure. Polyesters and alkyds are versatile resins for producing industrial coatings. The stability of some of these coating systems has been studied particularly under outdoor conditions $[1,8]$. However; the stability of polymeric materials under some elevated temperatures has not been reportedly studied. Consequently, there is no readily available information on the temperature range under which a particular coating is stable or what happens to the properties of the coatings when they are heated to some temperatures above room temperature. A probable reason for lack of such information could be that most coatings are commonly used at the ambient conditions and not much is needed for their utility at higher temperatures. But it is a common view, for instance, that stainless steel materials become rusted after a period of time during routine contact with air and water. This could be avoided if the materials are appropriately coated.

Organotin compounds have long been recognized as processing and/or service stabilizers for some polymers particularly PVC $[2,7,15,9,16]$. However, their roles as stabilizers for surface coatings have recently been receiving attention[1,8]. Such studies had concentrated on the use of organotin compounds of higher carboxylic acids and none for the lower acids. Also works on such stabilizers have been carried out under natural weather conditions and any for thermal environment has not been reportedly studied. The possibility of using some equipment at high temperatures would require coating them so as to reduce or eliminate some undesirable thermal effects on their properties and service life. Hence, the required coatings should be generally table at relatively high temperatures.

We have therefore embarked on a series of studies that will determine and document the physical and mechanical properties of some commercial paints at elevated temperatures. The temperature bracket suitable for a coating will therefore be available for paint users. Some additives are being synthesized and tested as possible paint stabilizers for coatings intended for service life under thermal conditions. In this study dibutyltin diethanoate was synthesized and tested as thermal stabilizer for two industrial paints. It is our goal to expand the utility level and stabilization technology of different commercial paints under certain exposure conditions.

\subsection{Materials}

\section{Experimental}

The test polyester was a saturated polyester resin, Uralac SN 831, (PET) manufactured by DSM Resins, Lagos, Nigeria. The alkyd tested was a long oil alkyd resin based on soybean, AR 3570W, manufactured by Nycil Ltd, Lagos, Nigeria. The polyester and alkyd coatings are herein referred to as PET and AR respectively. The pigment used was Syncomine yellow 1630, an inorganic yellow pigment, supplied by Berger Paints Plc, Lagos, Nigeria. The thinners were 2-methoxyethanol for the polyester and gasoline, dried over fused $\mathrm{CaCl}_{2}$, for the alkyd. All other chemicals were of analytical grade.

\subsection{Synthesis of dibutyltindiethanoate(DBTDET).}

The synthetic route involved substitution reaction between dibutyltin chloride, dissolved in minimum amount of diethyl ether, and potassium hydroxide. in minimum amount of distilled water, to form dibutyltin di- 
hydroxide $\left(\mathrm{Bu}_{2} \mathrm{Sn}(\mathrm{OH})_{2}\right)$ and $\mathrm{KCL}$. The salt was completely removed by several washings with distilled water until washing that gave negative chloride ion test with $\mathrm{AgNO}_{3}$ solution. Thermal dehydration of the $\mathrm{Bu}_{2} \mathrm{Sn}(\mathrm{OH})_{2}$ to constant weight gave dibutyltin oxide which on esterification with ethanoic acid yielded the dibutyltin diethanoate.

$$
\begin{aligned}
& \mathrm{Bu}_{2} \mathrm{SnCl}_{2}+2 \mathrm{KOH} \longrightarrow \mathrm{Bu}_{2} \mathrm{Sn}(\mathrm{OH})_{2}+2 \mathrm{KCI} \\
& \mathrm{Bu}_{2} \mathrm{Sn}(\mathrm{OH})_{2} \underset{\text { oven }}{\longrightarrow} \mathrm{Bu}_{2} \mathrm{SnO}+\mathrm{H}_{2} \mathrm{O}
\end{aligned}
$$$$
\mathrm{Bu} 2 \mathrm{SnO}+2 \mathrm{CH}_{2} \mathrm{COOH}
$$$$
\text { DBTO }
$$

\author{
$\mathrm{Bu}_{2} \mathrm{Sn}\left(\mathrm{OCOCH}_{3}\right)_{2}+\mathrm{H}_{2} \mathrm{O}$ \\ Dibutyltin diethanoate
}

The white solid $\mathrm{Bu}_{2} \mathrm{Sn}\left(\mathrm{OCOCH}_{3}\right)_{2}$, was purified by recrystallization from cyclohexane.

\title{
2.3 Characterization of DBTDET
}

It was characterized by FTIR Spectroscopy ((Model 1500,Buck Scientific Co, USA IR spectrometer), determination of melting point. and tin analysis. The method of Farnsworth and Percola[3] was used for the tin analysis with the following expression for determination of the tin content:

$\% \mathrm{Sn}=100 \mathrm{M}_{\mathrm{r}(\mathrm{Sn})} \mathrm{W} / \mathrm{Mr}_{(\mathrm{SnO} 2)} \mathrm{W}_{\mathrm{o}}$

Where; $\mathrm{M}_{\mathrm{r}}$ is molar mass, $\mathrm{W}$ and $\mathrm{W}_{\mathrm{o}}$ are the experimental weights of $\mathrm{SnO}_{2}$

and DBTDET respectively.

\subsection{Formulation of Coatings}

Formulation of coatings was based on pigment-binder $(\mathrm{PB})$ ratio[5] of 1:9. The stabilized samples contained 5, 10 or $20 \times 10^{-4}$ mole \% of DBTDET added to $100 \mathrm{~g}$ of the polyester or alkyd resin. Hence, the term mole $\%$ as used previously[5]. The coating sample without the additive served as the control.

To each formulation was added $75 \mathrm{~cm}^{3}$ of the thinner followed by stirring mechanically for 100 minutes in a water bath thermo-stated at $35^{\circ} \mathrm{C}$.

\subsection{Application of Paint and Detachment of dry coatings}

Clean glass panels $(10 \mathrm{~cm} \times 5 \mathrm{~cm} \times 0.2 \mathrm{~cm})$ were used as the substrate for each formulation. $10.0 \mathrm{~cm}^{3}$ of each liquid paint was applied onto the glass sheet placed at $180^{\circ}$ on a laboratory bench (for uniform thickness). The use of glass panels was to obtain free films for determination of mechanical properties[6] and smooth onsubstrate application for determination of gloss. The paint was allowed to dry at room temperature.

A clean razor blade was employed to detach the coatings. Appropriate sizes of the coatings were used for the study on mechanical properties,

\subsection{Oven ageing of coatings}

Both the polyester and alkyd coatings were subjected to thermal aging separately at $60^{\circ} \mathrm{C}$ and $100^{\circ} \mathrm{C}$ respectively in a Wallace air-circulating oven as described previously[7]. These two temperatures were determined as follows: The glass plates containing the coatings were hung vertically in the oven using ironclips. All the coatings of the polyester were hung at a particular temperature, say, $30^{\circ} \mathrm{C}$ in the oven for $2 \mathrm{~h}$. The adhesion failure and softening of the coatings were observed. The temperature was increased by $10^{\circ} \mathrm{C}$, the samples hung for another $2 \mathrm{~h}$ and observations made on the two parameters. This was repeated until the temperature of softening or adhesion, if any, occurred. Similarly, the alkyd coatings were treated separately. By this procedure, the experimental temperatures for aging the PET and AR coatings were determined as $60^{\circ}$ and $100^{\circ} \mathrm{C}$ respectively.

\subsection{Determination of gel content}

The gel content of the polyester or alkyd coatings at $\mathrm{O}$ and $500 \mathrm{~h}$ oven ageing was determined as described previously[8]. The solvents employed were as mentioned under materials. The procedure gave the quantities used for the determination of gel content from the following expression:

Gel content $(\%)=\mathrm{M}_{1} / \mathrm{M}_{\mathrm{o}} \times 100$

Where $M_{1}$ is the mass of insoluble fraction prior to and after aging time and $M_{o}$ is the initial mass of coating sample. 


\subsection{Color development}

The visual observation of any color development of the coatings before and after aging was carried out as described previously[5].

\subsection{Determination of Gloss retention}

The gloss level of each coating before and after thermal aging was determined using a $60^{\circ}$ gloss meter as described elsewhere[8].

\subsection{Measurement of Stress - Strain relationship}

The stress - strain curves were obtained using an Instron tensile machine 1026. Films of $2 \mathrm{~cm}$ gauge length, $1 \mathrm{~cm}$ wide and similar thickness were employed. A maximum shear load of $20 \mathrm{Kg}$ with chart to cross head ratio of 2:1 and cross - head speed of $100 \mathrm{~mm} \mathrm{~min}^{-1}$ were used.

\subsection{Optical microscopy}

An optical microscope model LEIT 2 Ortholux 2 pol. $\mathrm{B}_{4}$ was used as described earlier[5]. The coatings, as on the glass substrate, were used. With the aid of a marker, faintly drawn small circles $(1 \mathrm{~cm}$ diameter) were made on the coatings. A photograph of the center of the circle on the coating was taken prior to aging (0h) and at the end of 500h aging. The coatings were carefully and gently brushed-over to remove dust particles before they were photographed.

\subsection{Characterization of DBTDET}

\section{Results And Discussion}

The results shown in Table 1 below; Indicate that the test stabilizer used in this study was dibutyltin diethanoate and attested to a creditable synthetic route of the tin ester.

Table 1. Characteristics of Dibutyltin diethanoate

\begin{tabular}{ll}
\hline Parameter & Value \\
\hline Yield $(\%)$ & 95 \\
Appearance & white crystalline solid \\
M.pt. $\left({ }^{\circ} \mathrm{C}\right)$ & 58 \\
$\%$ Sn & 33.85 (Calculated):33.83(Found) \\
$v(\mathrm{Sn}-\mathrm{Bu})$ rock & $664.5 \mathrm{~m}$ \\
$v(>\mathrm{C}=\mathrm{O})$ assym.stretch & $1604.5 \mathrm{~s}$ \\
$v(\mathrm{Sn}-\mathrm{C})$ stretch & $1014.3 \mathrm{w}$ \\
\hline
\end{tabular}

\subsection{Thermal behavior of Coatings}

The heat tolerance, color and adhesion are important properties to be considered for coatings under any service life including thermal environment. Fig. 1 shows the effect of additive concentration on the softening temperature of the non-stabilized (control) and

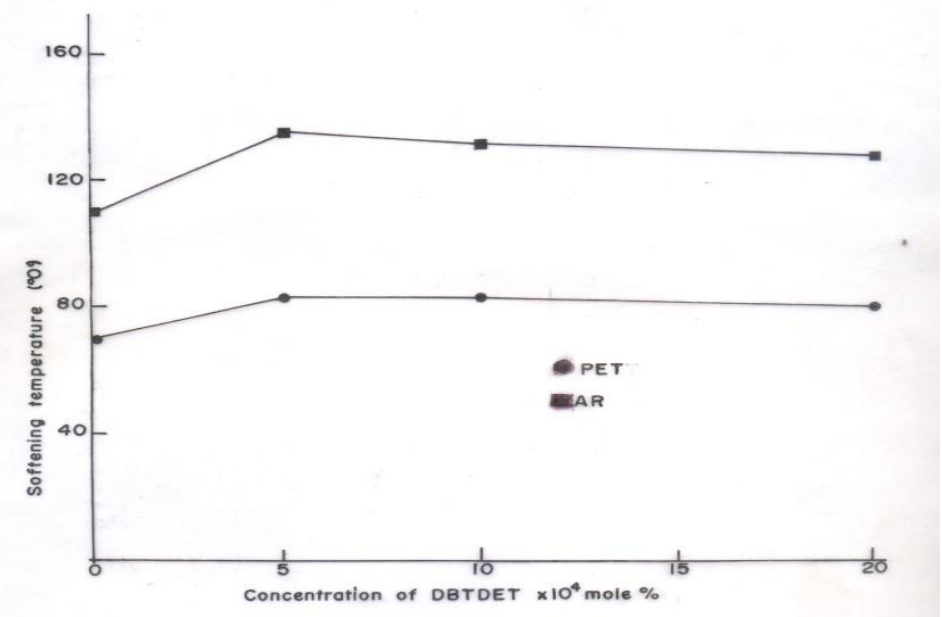

Figure 1. Effect of concentration of DBTDET on softening point of PET

stabilized samples of PET and AR coatings. It can be seen that the presence of the tin ester (DBTDET) imparted higher resistance towards thermal softening in the two types of coatings. The highest softening temperature was $83^{\circ} \mathrm{C}$ for the PET samples containing 5 or $10 \times 10^{-4}$ mole \% DBTDET. At $20 \times 10^{-4}$ mole $\%$ of the additive, plasticization might have set in resulting into lower softening temperature of $79^{\circ} \mathrm{C}$. 
Similar trend of tolerance to heat was observed for the alkyd coatings in which the samples containing $5 \times 10^{-4}$ mole $\%$ of DBTDET had the highest softening temperature of $135^{\circ} \mathrm{C}$. At all temperatures the AR samples are more tolerant to softening than the PET samples. The above differential observations between the two types of coatings might be attributed to the network of cross-linked chains with concomitant rigidity of the alkyd resins compared to the essentially linear chains of polyesters. And for both resins none of the coatings experienced adhesion failure throughout the period of aging for $500 \mathrm{~h}$.

\subsection{Effect of thermal aging on gel content.}

Fig. 2 shows that oven aging generally led to formation of more gel in the PET coatings before and after aging. Scheme 1 shows the reactions leading to the formation of two types of gel. The greater increase in gel that occurred in the stabilized samples was an indication of thermal homolysis of the tin-oxygen bond in the tin ester in line with previous work[10,8,7,5]. The heat also led to formation of the macroalk radicals. The subsequent reactions led to formation of the unstable peroxide cross-linked gel(POOP) while stabilizing reactions most probably culminated in the formation of the more stable tin cross-linked gel.

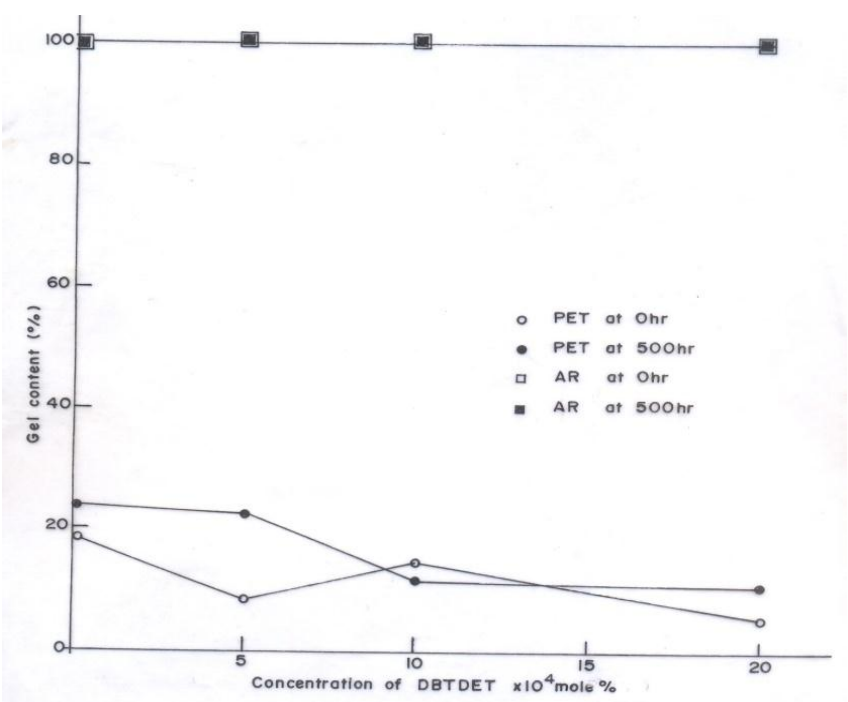

Figure 2 Effect of concentration of DBTDET on Gel content of PET

The presence of the tin ester alone, without heating, apparently attenuated the attractive force (plasticization) between the PET chains and reduced the tendency towards cross-linking reaction as evident from Fig.2 .And except at $10 \times 10^{-4}$ mole $\%$ of the tin ester the thermal treatment led to increase in gel content. On the other hand, the unstable peroxide (POOP)decomposes to carbonyl groups with decrease in chain length are expected in agreement with a previous work[5]. Oven aging in the presence of, particularly at $5 \times 10^{-4}$ mole $\%$, yielded $13.9 \%$ increase in gel content.

$$
\begin{aligned}
& 2 \mathrm{PH}+\mathrm{Bu}_{2} \mathrm{Sn}\left(\mathrm{OCOCH}_{3}\right)_{2} \longrightarrow \text { heat } \longrightarrow \mathrm{P}-\mathrm{Sn}(\mathrm{Bu})_{2}-\mathrm{P}+2 \mathrm{CH}_{3} \mathrm{COOH} \\
& 2 \mathrm{PH}+2 \mathrm{O}_{2} \rightarrow \mathrm{POOP}+\mathrm{HOOH} \text { (unstable products) } \\
& \mathrm{POOP} \text { heat } 2 \mathrm{P}=\mathrm{O}
\end{aligned}
$$

Scheme 1: Formation of gel in $\mathrm{PH}$ (polyester or alkyd)

It is worth noting that the $10 \times 10^{-4}$ mole \% coating sample that had the greatest gel content before aging, among the stabilized samples, now possessed the least content among all the coatings after aging. The reason for this is not clear. The study on mechanical properties may probably confirm this. The gel obtained from the $20 \times 10^{-}$ ${ }^{4}$ mole $\%$ coating had a tinge of reddish color.

\subsection{Effect of Oven aging on color of the coatings}

The table below; shows the color characteristics obtained during the thermal aging

Table 2. Effect of thermal aging on color of coatings.

\begin{tabular}{lcccc}
\hline & \multicolumn{4}{c}{ Color development } \\
\cline { 2 - 4 } & & \multicolumn{4}{c}{ PET } & Oven aging(hr) \\
\hline Sample & 0 & 500 & 0 & 500 \\
\hline
\end{tabular}




\begin{tabular}{|c|c|c|c|c|}
\hline Contro & llow & Yellow & Yellc & Red \\
\hline PB $1: 9+5 \times 10^{-4}$ mole $\%$ DBTDET & Yellow & No change & Yellow & No \\
\hline PB $1: 9+10 \times 10^{-4}$ mole $\%$ DBTDET & Yellow & No change & Yellow & No change \\
\hline PB $1: 9+20 \times 10^{-4}$ mole $\%$ DBTDET & T Reddish ye & w No change & Yellow & No change \\
\hline
\end{tabular}

of both the unstabilized and stabilized PET and AR coatings. It can be seen that the yellow color of the syncomine 1630 pigment can be stabilized effectively when 5 or $10 \times 10^{-4}$ mole \% DBTDET is incorporated into either the PET or AR coatings. Thermal aging could have effected some motion of the polymer chains in the coatings allowing the pigment molecules to be more effectively distributed and enhanced the cohesion of the resin chains together. This maintained the yellow color particularly in the presence of the tin ester at the effective concentrations.

At $20 \times 10^{-4}$ mole $\%$ of the additive the color of the PE coating changed to reddish brown which was maintained even after aging. The excess of the additive at this concentration could be responsible for some plasticization that enhanced heat flow into the polymer matrix engendering some color destabilization during drying and aging. A reddish color tinge was earlier observed in the gel obtained from the $20 \times 10^{-4}$ mole $\%$ coating. The color change could also be due to the effect of thermal aging on the additive molecule resulting into formation of excess radicals at this concentration. These radicals could attack a hydrogen atom on the polymer backbone leading to oxidation of the polymer and color deterioration in line with an earlier explanation[10].

\subsection{Effect of Oven aging on the gloss of coatings}

Fig. 3 shows that oven aging decreased the gloss of all the PET and AR coatings. The level of gloss degradation in the PET generally less than that that of the AR coatings. However; prior to and after aging the gloss retentions of all the stabilized samples were greater than that of the control. For both the PET and AR samples the presence of $5 \times 10^{-}$ ${ }^{4}$ mole \% DBTDET imparted the greatest level of gloss before and after aging. The relatively low levels of gloss obtained here are well known of non-modified alkyd and polyester coatings and as such they can be the semigloss type in agreement with previous classification[11]. The present result is in agreement with the earlier section on gel retention demonstrating the dependence of gloss retention on gel content in agreement with a recent work[8].

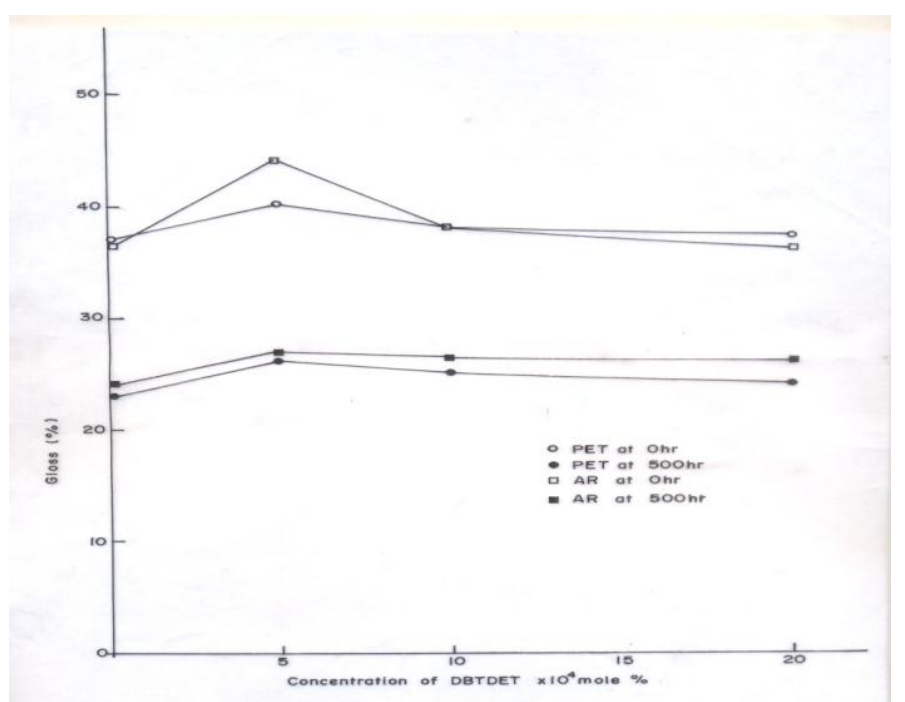

Figure 3 Effect of concentration of DBTDET on gloss on PET

\subsection{Stress- Strain relationship of PET and AR coatings. 3.6.1 PET Coatings}

The stress-strain curves of both the non-stabilized and the stabilized PET samples prior to and after oven aging are shown in Fig.4.There is a threshold stress for each coating sample at zero strain. 


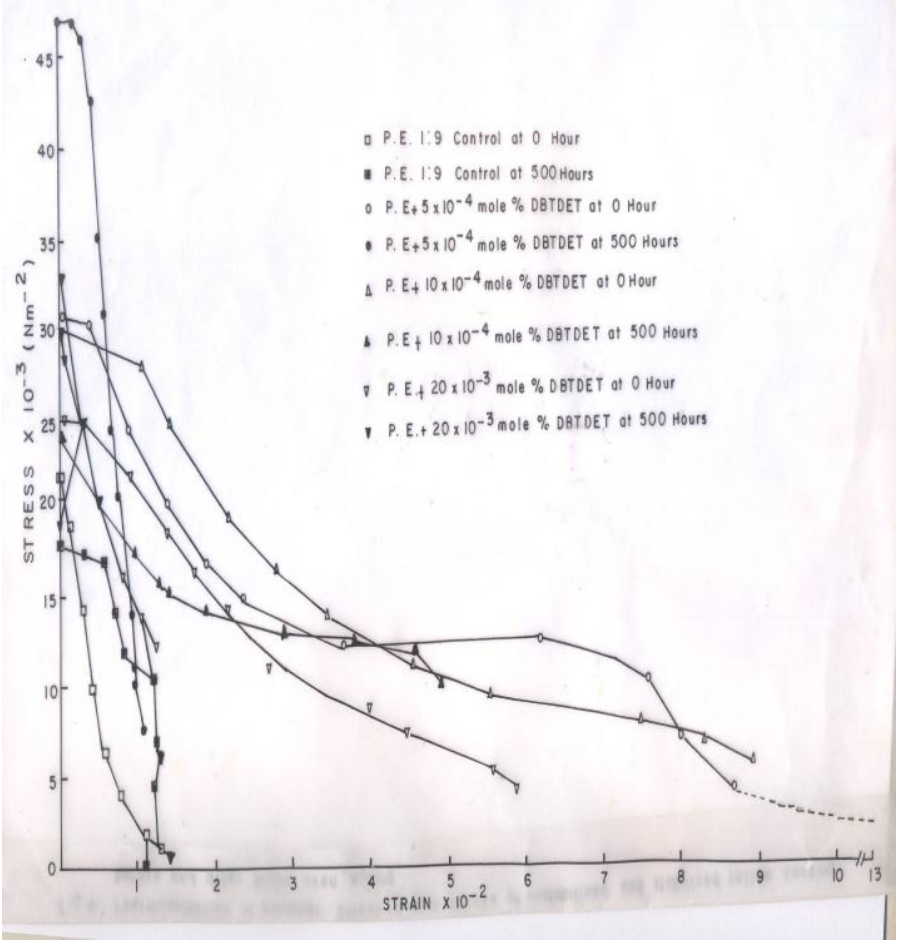

Figure 4 Stress-Strain curve of unstabilized and DBTDET stabilized PET.

tensile yield stress of each of the stabilized samples is greater than that of the control sample. Prior to aging, the stress of the coatings decreased with increasing concentration of DBTDET, that is, $31 \times 10^{3}, 30.5 \times 10^{3} 25 \times 10^{3}$ $\mathrm{Nm}^{-2}$ for samples containing 5,10 and $20 \times 10^{-4}$ mole \% DBTDET respectively while the control sample had yield stress of $22 \times 10^{3} \mathrm{Nm}^{-2}$-Before aging, the elongation at break unexpectedly followed similar order i.e. $1300 \%$, $900 \%, 600 \%$ and $160 \%$ for the samples containing 5,10 and $20 \times 10^{-4}$ mole $\%$ of the tin ester and the control sample respectively. After oven aging, it can be seen that all the stabilized samples had higher tensile yield stress than the control sample. The latter sample had the least value of $18.5 \times 10^{3} \mathrm{Nm}^{-2}$ followed by samples containing 10, 20 and $5 \times 10^{-4}$ mole\% DBTDET with 24,33 and $47.5 \times 10^{3} \mathrm{Nm}^{-2}$ yield tensile stress respectively. Thus after oven aging, the sample containing 5 and $20 \times 10^{-4}$ mole\% DBTDET had enhanced yield stress while that of $10 \times 10^{-4}$ mole $\%$ coating decreased, at less than $100 \%$ elongation at break. Beyond this level of elongation, the sample containing the $10 \times 10^{-4}$ mole \% DBTDET persisted with greater stress values compared to other samples including the control.

Amongst the stabilized samples the trend in tensile stress is generally similar to the changes in gel content after oven aging (Fig.2). For instance, the samples that had increases in gel content i.e. $5 \& 20 \times 10^{-}$ ${ }^{4}$ mole \% samples with 5.9 and $5.6 \%$ increase respectively also had higher tensile yield stress values of 47.5 and $33 \times 10^{3} \mathrm{Nm}^{-2}$ respectively. On the other hand, the sample containing $10 \times 10^{-4}$ mole \% DBTDET which had reduction of $6.8 \mathrm{Nm}^{-2}$ in stress also had a slight decrease in gel content $(1.7 \%)$ after oven aging. The converse of this trend generally existed with the elongation at break, \% (EB). Though all the samples experienced decreasing strain during oven aging, the samples that had the greatest gel formation had the shortest elongation at break and vice versa. For instance, the coating containing $10 \times 10^{-4}$ mole $\%$ of DBTDET that had decrease in gel content had the longest residual elongation at break (490\%) after oven aging. The $5 \times 10^{-4}$ mole\% sample containing the highest increase in gel content $(18.9 \%)$ had the least elongation at break of $110 \%$ after aging (Figs. $2 \& 4$ ). These results on the stress-strain confirmed the earlier result on gel content of the $10 \times 10^{-4}$ coating which was the only one with reduced gel content during oven aging. This shows that the nature, quality and quantity of gel most probably determine the mechanical properties of the polyester coating similar to an earlier work with alkyd coatings, [8]. But then the control sample containing the least yield stress $\left(18.5 \mathrm{Nm}^{-2}\right)$ and strain of $130 \%$ at break had an increase in gel content after aging (Fig.2). One would have expected the control sample with its increased gel content after aging to have had increased yield stress but rather its stress was reduced from 22 to $18.5 \mathrm{Nm}^{-2}$ (Fig.4). The reason for this could be attributed to the differences in the chemical composition of the gel of the control (POOP) and that of the stabilized samples (P-Sn-P).The former gel was greater in quantity but less strong than that of the organotin gel. 


\subsubsection{AR Coatings}

Fig. 5 shows that the control sample had the least tensile yield stress prior to aging compared to the stabilized samples. The pre-exposure effectiveness of the tin ester in enhancing the stress is not concentration dependent. The $5 \times 10^{-4}$ mole $\%$ sample had the highest yield stress followed by the $20 \times 10^{-4}$ mole $\%$ sample and then the sample containing $10 \times 10^{-4}$ mole $\%$ of the tin ester. The oven aging of the samples led to increased tensile stress for all the samples including the control. Thus the initial stress of the control increased from 8 to $28 \times 10^{3} \mathrm{Nm}^{-2}$ i. e. $20 \times 10^{3} \mathrm{Nm}^{-2}$ increase, that of $5 \times 10^{-4}$ mole \% sample increased from 26 to $65 \times 10^{3} \mathrm{Nm}^{-2}$ i.e. $39 \times 10^{3} \mathrm{Nm}^{-2}$ increase, the $10 \times 10^{-4}$ mole \% sample had its tensile stress increased from $18 \times 10^{3}$ to $44 \mathrm{Nm}^{-2}$ i.e. $26 \times 10 \mathrm{Nm}^{-2}$ increase and the $20 \times 10^{-4}$ mole $\%$ sample from 22 to $38 \times 10^{3} \mathrm{Nm}^{-2}$ i.e. $16 \times 10^{3} \mathrm{Nm}^{2}$ increase. Therefore, amongst the stabilized samples, tensile stress decreased with increasing concentration of DBTDET after oven aging. Expectedly, after oven aging the alkyd samples that had relatively high tensile stress generally had low strain at break. Thus the samples became tougher and stiffer with oven aging [12].

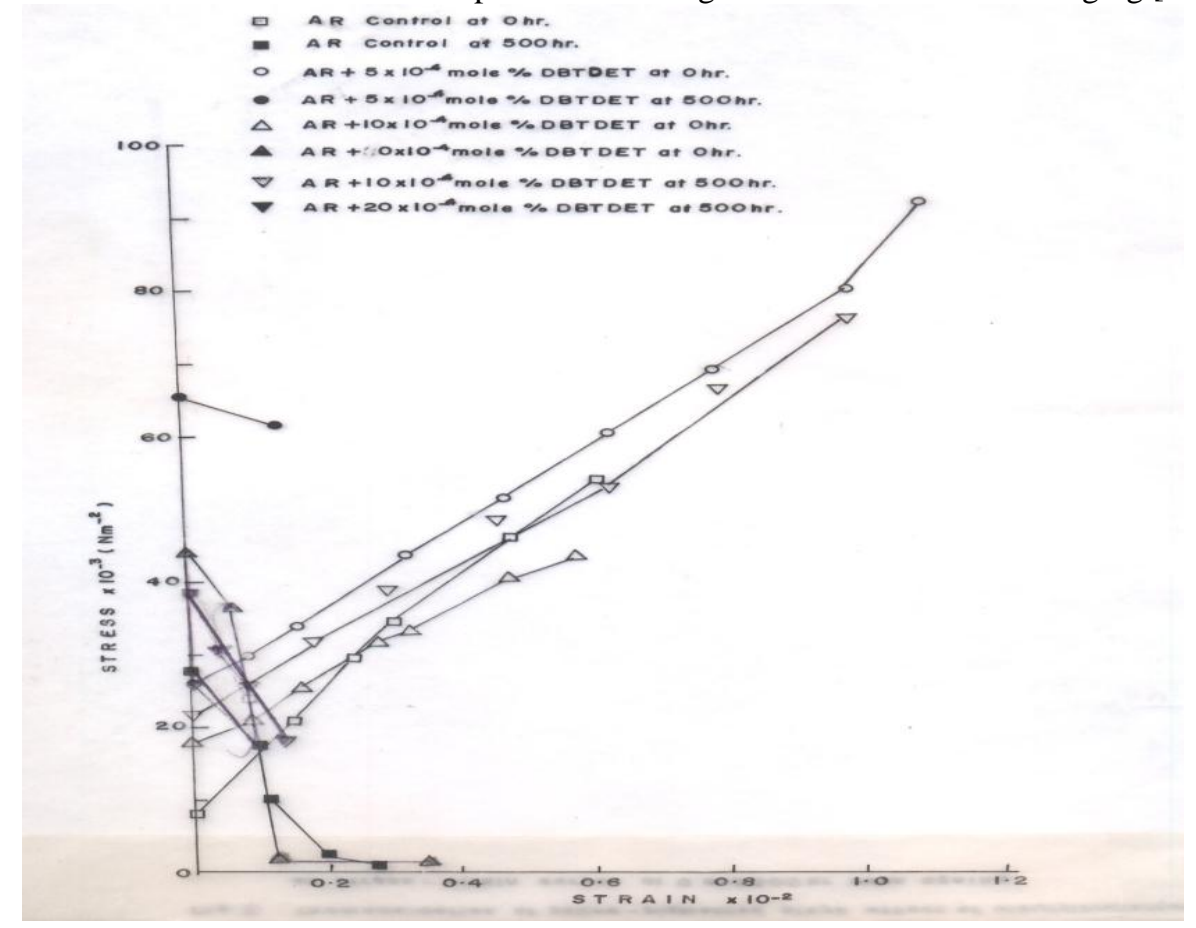

Figure 5 Stress-Strain curves of unstabilized and DBTDET stabilized AR

These results further suggest and emphasize that the nature of the cross-links in the un-stabilized samples differs from those of the stabilized samples. The cross-links in the un-stabilized samples are most probably the thermally induced peroxy gel while those of the stabilized samples essentially consist of dibutyltin moiety (Scheme 1). The steric effects due to the two bulky butyl groups in DBTDET and the bigger atomic size of tin atom compared to oxygen as well as the relative bond strength of the C-Sn and C-O, the former being greater ${ }^{13}$ are probably the most important factors that determine the relatively high mechanical strength of the stabilized coatings. The $10 \times 10^{-4}$ mole $\%$ of the tin ester is particularly useful for enhancing the elongation at break during oven aging. This means substrates coated with syncomine 1630 pigmented PET or AR resin and stabilized with this amount of DBTDET would be better protected during oven aging.

\subsection{Optical micrographs (OMG) of PET and AR coatings}

The OMG of the coatings before and after aging gave structural evidences that can be correlated with the mechanical properties discussed so far in this study. Before aging, Fig.6 (a) showed compartmentalized structures in the control. This could facilitate diffusion of oxygen into the polymer matrix via the linings and favored formation of peroxy cross-linked gell.

The demarcations had disappeared after aging Fig. 6(b) probably due to thermally induced 


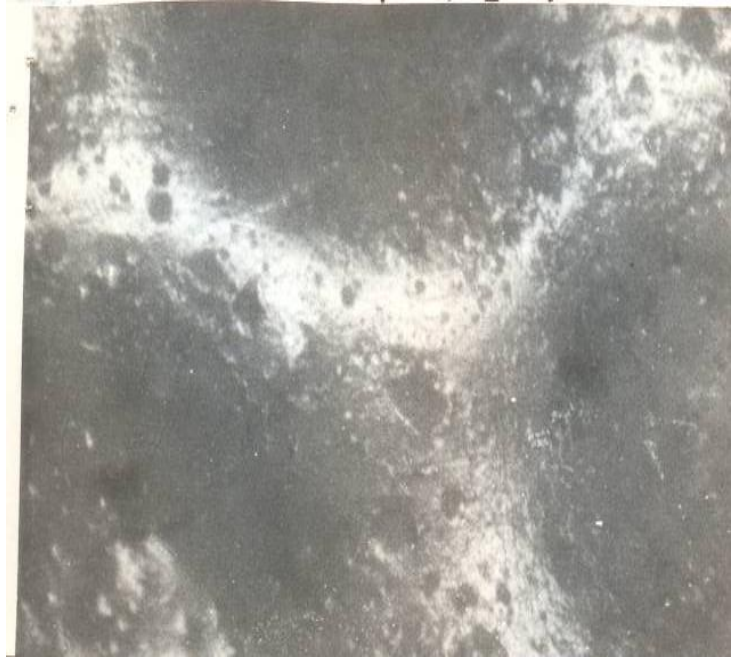

Figure 6(a)

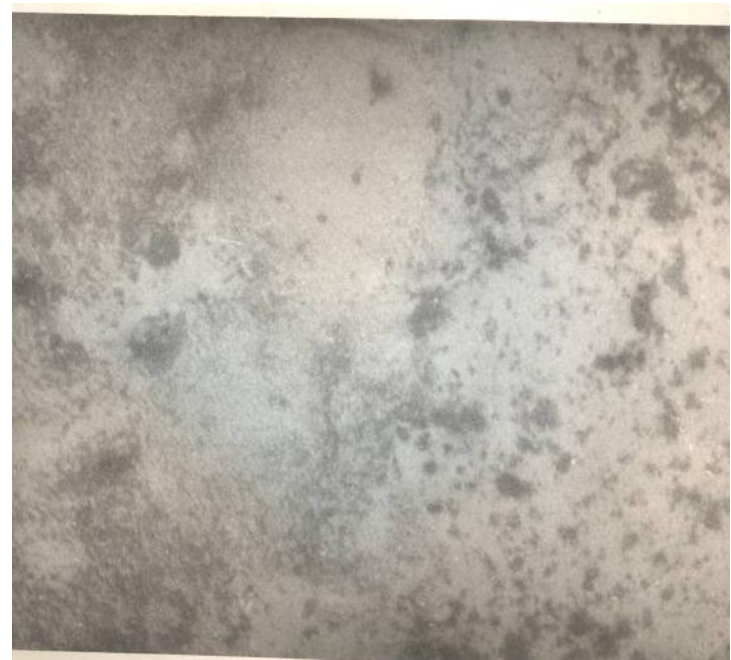

Figure 6(b)

Figure 6 Effect of thermoxidative aging on PET control coating (a)before and (b)after aging at $100^{\circ} \mathrm{C}$

chain motion, resulting into segregated fused structures after aging. These features and changes might account for the relatively low mechanical properties of the control sample after aging. There is a fairly uniform distribution of the molecules of DBTDET in all the stabilized PET coatings as represented by that of $5 \times 10^{-4}$ mole \% in Fig. 7(a) without the demarcations found in the control. Such distribution could be responsible for the effectiveness of the tin ester in

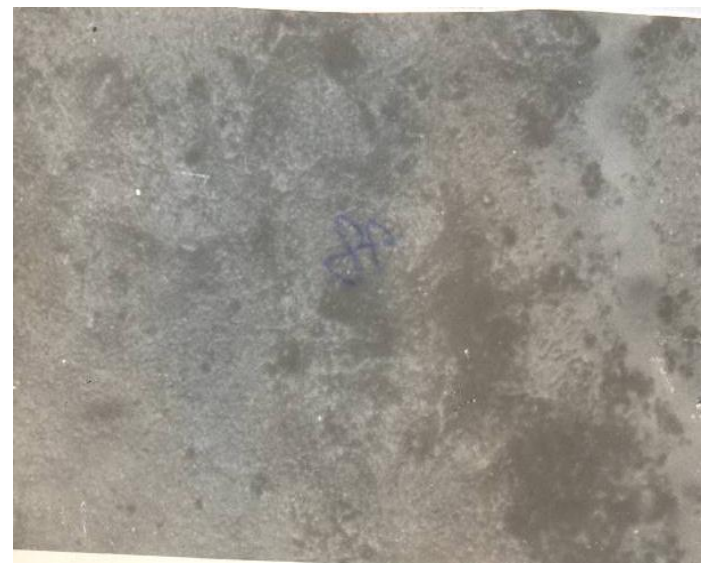

Figure 7(a)

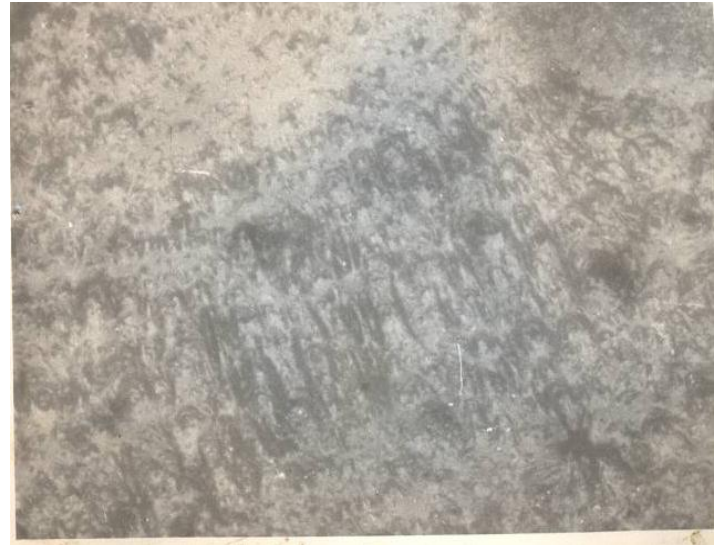

Figure 7(b)

Figure 7. Effect of thermoxidative aging on PET coating stabilized with $5 \times 10^{-4}$ mole\% DBTDET (a)before and (b)after aging at $\mathbf{1 0 0}^{\circ} \mathrm{C}$

limiting the oxidative degradation of the PET coatings in line with a previous work ${ }^{5}$. This enhances the stabilizing activity of the additive producing coatings with improved mechanical properties as found for the PET samples stabilized with 5 or $10^{-4}$ mole\% DBTDET. 
Fig. 8(a) and (b) are the OMG of the control of alkyd samples before and after aging. There was apparent homogeneous chain decomposition after aging as reflected in corresponding relatively low yield stress and elongation at break of these coatings as reported in the earlier section. In contrast, Fig.9 (a) is the micrograph of the non-exposed stabilized samples in which the polymeric chains were still available along with the distributed particles of the additive.

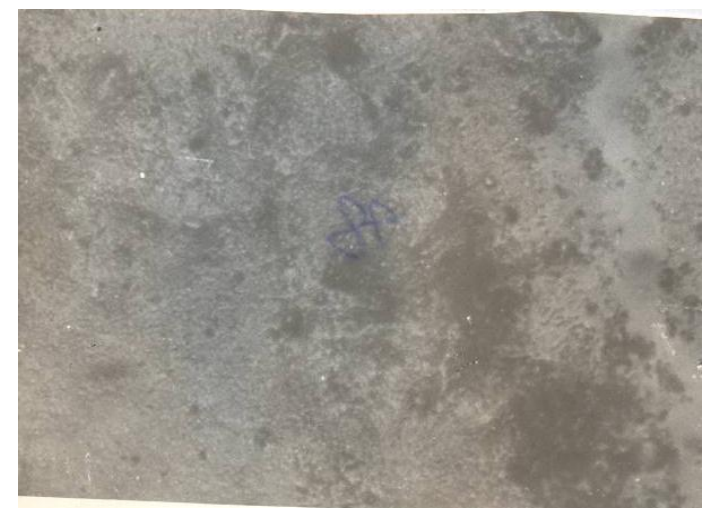

Figure 8(a)

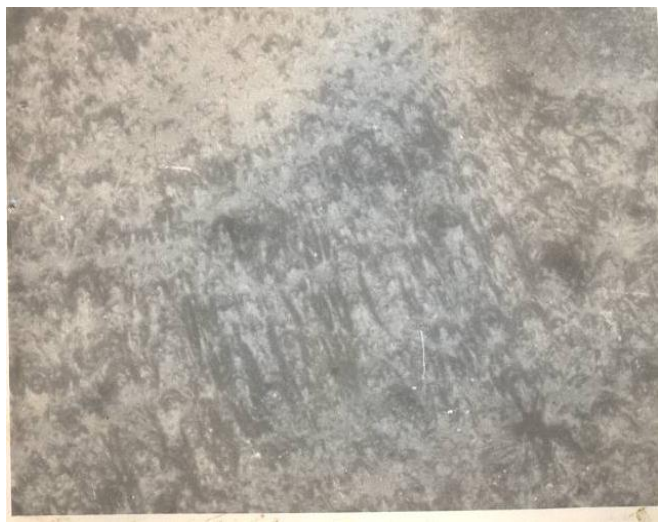

Figure 8(b)

Figure 8. Effect of thermoxidative aging on AR control coating (a) before and (b) after aging at $100^{\circ} \mathrm{C}$

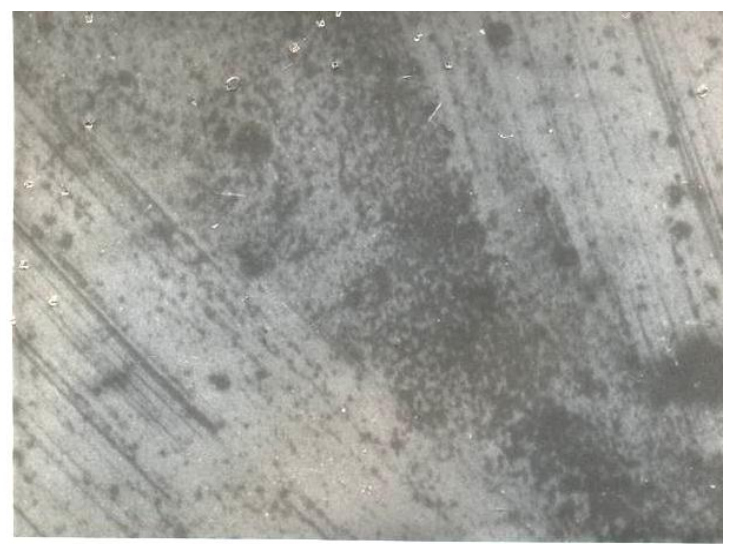

Figure 9(a)

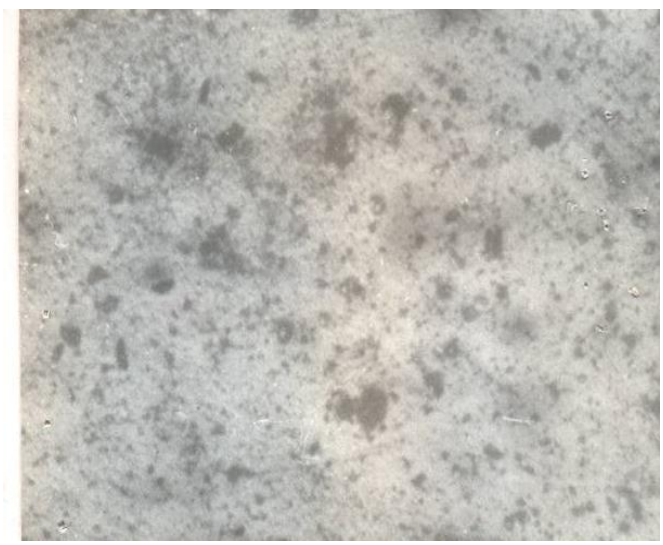

Figure 9(b)

Figure 9. Effect of thermoxidative aging on AR coating stabilized with $5 \times 10^{-4}$ mole $\%$ DBTDET (a) before and after aging at $100^{\circ} \mathrm{C}$

It is observed in the OMG of the alkyd samples (only that of $5 \times 10^{-4} \mathrm{~mole} \%$ is shown here), that the level of availability of these chains is in the order: $5 \times 10^{-4}>>20 \times 10^{-4}>10 \times 10^{-4}$ mole \% DBTDET coatings and none for the control due to greater level of degradation. This is the same order of the yield stress of the samples prior to aging (Fig 4). Most of the polymeric chains probably had degraded to smaller forms after aging Fig. 9(b). These, having greater surface areas could result into better distribution and interaction of the additive with the polymer matrix as aging progressed. Consequently, there would be greater cohesive forces between the polymeric residues, particularly at the surfaces where oxidative degradation is expected to be faster in line with a previous work[14]. There were low strains at break for all the samples which could be due to shorter macromolecular chains obtained during the thermal aging. Thus oven aging made the stabilized coatings harder and stronger[12].

\subsection{Comparative properties between the polyester and alkyd coatings}

The table 3; Shows comparison between the properties of the coatings of the yellow polyester 
Table 3. Comparative analysis of properties of polyester and alkyd

\begin{tabular}{|c|c|c|c|c|}
\hline & \multicolumn{2}{|c|}{ Polyester(UralacSN831) } & \multicolumn{2}{|l|}{ Alkyd(AR3570) } \\
\hline Parameter & Control & Stabilized(MEF $\left.{ }^{\mathrm{a}}\right)$ & Control & Stabilized(MEF*) \\
\hline Color(RMT) & Pale yellow & Yellow & Yellow & Yellow \\
\hline Color(aged,500h) & Pale yellow & Yellow & Reddish yellow & Yellow \\
\hline Softening Temp $\left({ }^{0} \mathrm{C}\right)$ & 70 & 83 & 110 & 135 \\
\hline Gel content,\%(RMT) & 5 & 40.5 & 100 & 100 \\
\hline Gel content $\%($ aged, $500 \mathrm{~h})$ & 23.9 & 12.8 & 100 & 100 \\
\hline Gloss retention, $\%(\mathrm{RMT})$ & 37 & 40 & 36 & 44 \\
\hline Gloss retention, $\%(500 \mathrm{~h})$ & 24 & 26 & 24 & 27 \\
\hline Yield stress, $\mathrm{Nm}^{-2} \times 10^{3}(\mathrm{RMT})$ & 22 & 31.5 & 8 & 26 \\
\hline Yield stress, $\mathrm{Nm}^{-2} \times 10^{3}$ (aged,500h) & 18.5 & 47.5 & 28 & 65 \\
\hline Elongation@break,\%(RMT) & 140 & 1300 & 61 & 110 \\
\hline Elongation@break\%(aged, & 130 & 490 & 26 & 38 \\
\hline
\end{tabular}

\section{MEF = Most Effective Formulation[10]}

and alkyd used in this study. The most effective coatings, as found in the earlier sections, amongst the stabilized samples were used for comparison with the control of each resin. It can be seen, among others, that:

1. The alkyd coatings generally had greater tolerance towards thermal softening than the polyester. This could be attributed to greater gel content in the alkyd.

2. Oven aging of the polyester coatings generally decreased the level of gel content whereas the exposure did not affect the gel content in the alkyd coatings even at the higher exposure temperature.

3. Oven aging led to decreased yield stress of the un-stabilized polyester coating while the stabilized samples generally experienced increased yield stress. On the other hand both the un-stabilized and stabilized alkyd coatings had increased yield stress during thermal aging. The enhancement in yield stress of the stabilized samples was greater for the alkyd than the polyester coatings. Both the un-stabilized and stabilized polyester coatings were more flexible than the alkyd coatings as evident from the greater strains at break. This could be attributed to the greater cross-linked gel present in the alkyd coatings. Dibutyltin diethanoate, particularly at $10 \times 10^{-4}$ mole $\%$, significantly enhanced the elongation at break of both the polyester and alkyd coatings.

\section{Conclusion}

Dibutyltin diethanoate is an effective thermoxidative stabilizer for the test polyester and alkyd coatings intended for service life at about 80 and $135^{\circ} \mathrm{C}$ respectively. Both the polyester and the alkyd coatings required 5 or $10 \times 0^{-4}$ mole\% (the latter if enhanced flexibility is desired) during exposure to thermo-oxidative aging. Without the additive, the polyester and alkyd would only be useful at about 60 and $100^{\circ} \mathrm{C}$ respectively.

Most of the useful properties of coatings are determined by the nature and quantity of the gel content in the polyester or alkyd which directly improved the tensile properties. The presence of dibutyltin diethanoate in the polyester coating generally enhanced formation of gel during oven aging resulting into greater tensile yield stress Thermoxidative aging generally led to better physical properties of the alkyd than polyester coating such as gloss retention and heat tolerance. The formulation consisting of polyester or alkyd,5x $10^{-4}$ mole \% DBTDET( based on the mass of resin to yellow syncomine 1630 at 1:9 PB and the appropriate thinner) would suffice to coat industrial materials intended for service life under thermo-oxidative conditions above the ambient temperatures.

\section{Acknowledgements}

We are very grateful to the Managing Director of the Berger Paints Plc, Lagos, Nigeria for the provision of the resins and pigments used in this study.

\section{Reference}

[1]. E.G Kolawole, J.J Bonire, O.A Peters, A.A Somorin, Turoti M., Weatherability of alkyd coatings. Part 1: Stabilization of poly pentaeryhritol-phthalate) based alkyd resin using dibutyltin dicarboxylates during outdoor exposure. Nigerian Journal of Polymer Science 2; 2001; 100-112.

[2]. F. Alavi-Moghadan, G. Ayrey, R.C Poller., The use of organotin compounds in the thermal stabilization of poly(vinyl chloride). A radio chemical study of reaction between PVC and di(butylthiolato)dibutyltin. EuroPolm; J.11(9), 1975, 649-651.

[3]. M. Farnsworth, J. Percola, Determination of Tin in inorganic and Organic compounds and mixture, Analytical Chem.1959, 31, pp.410..

[4]. J.F Rolinson 1987, Pigments for paint in Paint. In; R. Lambourne, (Ed). Surface Coatings (New York, John Wile \& Sons, 1987), pp111-193.

[5]. M. Turoti, J.B Adeniyi, J.Y Olayemi, O.A Peter, The thermo-oxidative degradation of poly(vinylchloride): 3.The stabilizing action of dibutyltinmaleateandtrisnitro(1,3-dihydoxy-2-hydroxymethyl-2-nitropropane). Effect of outdoor exposure on PVC. Polym Deg Stab. 63, 1999; 341-347. 
[6]. U.D Harkai, A.J Muelberg, J. Li, J.T Garret, D.C Webster, The influence of structural modification and composition of glycidyl carbamate resins on their viscosity and coating performance. J.Coat.Technol.Res. 7(5) 2010; 531-546.

[7]. O.A Peters, M. Turoti, J.B Adeniyi, The thermoxidative degradation of poly (vinyl chloride)Part 1. The stabilizing action of dibutyltin maleate and trisnitro (1,3-dihydroxy-2-hydroxymethyl-2-nitropropane ) on PVC in air. Polym Deg Stab 1(50) 1999; 175-182.

[8]. M. Turoti, C.E Gimba, S.S Achi, Environmental degradation of surface coatings: I. stabilization of green poly(glycerol-phthalate) based alkyd coatings with some dibutyltin dicarboxylates during outdoor exposure, 2010.

[9]. B.B Cooray, G. Scott, The role of tin stabilizers on the processing and service performance of PVC. Dev. Polym; Stab.25, 1980; 5372.

[10]. M. Turoti, The stabilizing effects of dibutyltin distearate on some properties of poly(glycerol-phthalate) based alkyd coatings exposed to outdoor weather. In Chemical Abstract, Nig. Journ. Chem. Res. 10, 2005; 31-39.

[11]. T.R Bullett, Specification and control of appearance. In: Lambourne, R, (Ed) Surface coatings. (New York, 2nd ed. JohnWiley \& Sons, 1987) pp.644-691.

[12]. E.A Collins, J. Bares, F.W Billmeyer Jnr, Experiments in Polymer Science. First Ed. (John Wiley and Sons, New York, 1973) pp.111-114.

[13]. G.E Coates, M. Green, L.H Powell, K. Wade, Principles of Organometallic Chemistry. (Willmer Brothers Ltd, Great Britain, 1968).

[14]. Z.O Oyman, W.R Ming, J. Van der Linde, A. Burg, J.R Schut Bielemen, Oxidative drying of alkyd paints catalysed by a dinuclear MnMeTACN. Surface Coatings International Part B: Coatings Transactions II, (B4) 2005; 269-275.

[15]. G. Spiliopoulus, M. Statheropopulus, G. Parissaltis, Mass spectroscopic study of the stabilization of PVC with dioctyltin dithioglycolic acid ester. Euro Polym J, 25(9) 1989; 989-991.

[16]. Z Vymazal, Z Vymazalova, Photo-degradation of PVC stabilized by organo tin compounds. Euro Polym J. 27(11) 1999; 12851290 . 